\title{
HOTEL INDUSTRY DEMAND CURVES
}

\author{
Jack Corgel \\ Jamie Lane \\ Mark Woodworth
}

\begin{abstract}
This research extends previous work on understanding hotel demand by focusing on the demand curve. Specifically, attention is directed toward the slope of the curve indicating the relationship between average daily rate (ADR) and the number of rooms sold - the price elasticity. Also, we investigate shifts in the curve caused by demand determinants such as changes in income, the extent is represented by income elasticity. Our findings are consistent with estimates produced by others for short-run elasticity, but we report sometimes noticeable differences between long-run and short-run elasticity. Price and income elasticity are considerably larger for higher quality hotels as indicated by the chain scale in which they operate. Elasticity tends to increase with data disaggregation. Higher elasticity is generally found for individual chain scales and cities compared to the nation.
\end{abstract}

\section{Introduction}

The PKF Hospitality Research, LLC (PKF-HR) Hotel Horizons ${ }^{\circledR}$ market forecasts come from estimating, then predicting with, a series of equations based on well-established economic and statistical principles. Arguably, the most important of these equations captures the relationships between hotel demand the number of rooms sold - and economic determinants of hotel demand. To be included in a demand equation, economic variables must 'make sense' from an economic theory perspective (i.e., be economically significant) and have a demonstrated statistically significant relationship with hotel 
demand. ${ }^{1}$ Smith Travel Research has collected data in the U.S. on the number of rooms sold covering nearly three hotel cycles (1988-2011) and Moody's Analytics sells extended time-series data on a large number of economic variables. Combining these data allows for the development, testing, and refinement of Hotel Horizons ${ }^{\circledR}$ demand equations. Using Moody's forecasts of economic variables and the statistical relationships between hotel demand and these economic variables, predictions of future levels of hotel demand are prepared.

The general form of the Hotel Horizons ${ }^{\circledR}$ demand equation is as follows:

Rooms Sold $=\mathrm{f}\left(\mathrm{ADR}\right.$, Income, Change in Employment, Seasonal Adjustments, Rooms Sold $\left.{ }_{-1}\right)$

Virtually all consumer goods and services demand equations include price and income measures. Hotel Horizons ${ }^{\circledR}$ equations incorporate hotel Average Daily Rate (ADR) and real personal income as determinants of hotel demand. The change in employment measure that appears in these equations aids in prediction during times when hotel demand changes while incomes remain flat and employment is changing. Exhibit 1 shows the expected direction of the relationship between hotel demand and each economic variable. For example, as ADRs increase, consumers purchase fewer hotel rooms, hence the negative sign. As income and employment increase, consumers have greater abilities to purchase hotels rooms, hence the positive direction of these relationships.

Exhibit 1: Independent Variable Relationships to Hotel Demand

$\begin{array}{ll}\text { Variable } & \text { Relationship to Demand } \\ \text { ADR } & \text { Negative } \\ \text { Income } & \text { Positive } \\ \text { Change in Employment } & \text { Positive } \\ \text { Seasonal Adjustment Factors } & \text { Positive or Negative } \\ \text { Rooms Sold }-1 & \text { Positive and }<1\end{array}$

\footnotetext{
${ }^{1}$ Hotel Horizons ${ }^{\circledast}$ includes over 100 demand equations, some of which have the same the variables and structure but many differ in some way to achieve the best statistical fit. Demand equations are produced for all hotels in the U.S., each of the six chain scales as categorized by Smith Travel Research, and both upper-priced and lower-priced hotels in the 50 largest metropolitan markets.
} 
We have two purposes for preparing this article. First, we review for readers the basic economic principles of consumer demand and apply them to the physical space and service bundle produced by hotels - the room night. Second, we conceptualize a series of demand curves for the hotel industry in 2012 including demand curves and elasticity estimates for all U.S. hotels, six chain scales, and selected metropolitan markets. By examining the signs and relative magnitudes of these estimates and how they differ in the long- and the short-run, we provide insights about the current demand conditions in U.S. hotel markets.

Published works on hotel demand focus on short-run price elasticity. The short-run elasticity estimates by PriceWaterhouseCoopers (2005) and Green and Lomanno (2011) resemble our short-run elasticity numbers. We contribute additional analysis of long-run price elasticity to enhance guidance for future pricing decisions.

\section{Price and Quantity Demanded}

The economic theory of consumer demand tells us that price and quantity demanded are inextricably linked. In hotel markets, periodic ADR is the price; and ADR largely determines how many rooms are sold during that period - the quantity demanded. Exhibit 2 graphically presents the demand curve found in introductory economics texts augmented here to reflect hotel price and quantity demanded. This curve $\left(D_{1}\right)$ has a negative slope to reflect the inverse relationship between ADR and rooms sold.

The slope of the demand curve $D_{1}$ represents the price elasticity of demand. Price elasticity is quantitatively defined as the percent change in quantity demanded divided by the percent change in price. Demand is said to be highly price elastic when the percent change in quantity demanded is large (i.e., highly responsive) given a modest change in price; then the elasticity is $>1$. Demand is price inelastic when quantity demanded doesn't respond very much to changes in price; then the elasticity < 1. The slope of the hotel demand curve in Exhibit 2 indicates neither a particularly price elastic nor inelastic demand for hotel rooms. Exhibit 3 shows the extreme cases of perfectly elastic $\left(D_{2}\right)$ and perfectly inelastic demand $\left(D_{3}\right)$ with respect to price. Moving up and down any of these curves indicates the number of rooms sold at a particular price.

Exhibit 2: Hotel Demand Curve

Exhibit 3: Perfectly Elastic and Inelastic Hotel

Demand Curves 


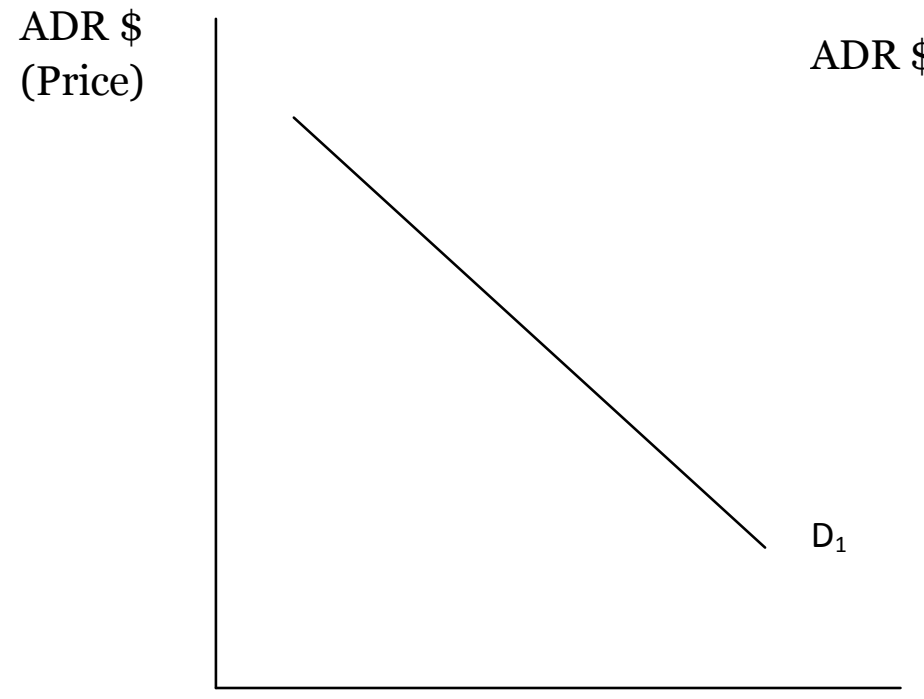

Number of Rooms Sold

(Quantity Demanded)

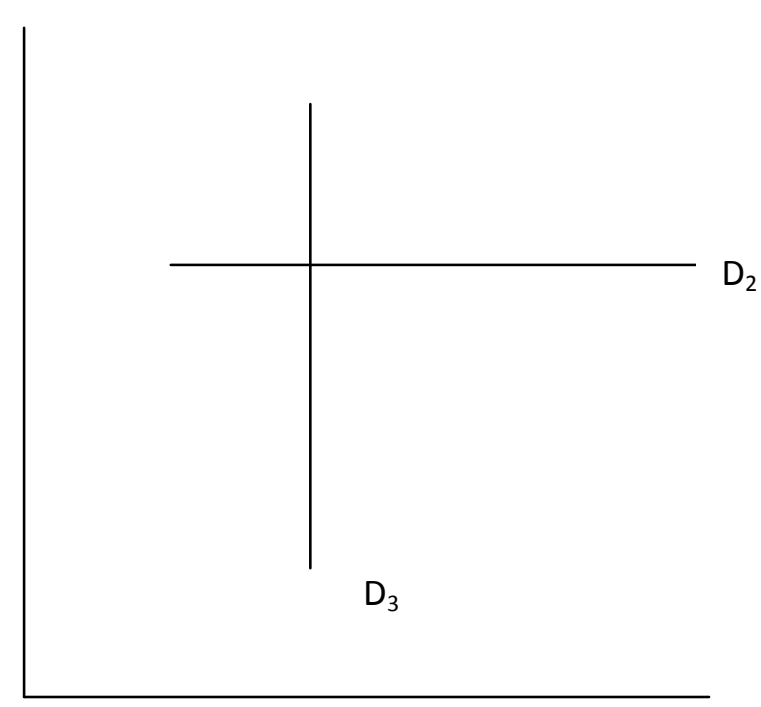

Number of Rooms Sold

\section{Computing Elasticity and Expected Results}

Price and income elasticity may be directly computed from estimated parameters of the demand equation (Equation 1) using regression to estimate these parameters once the levels of rooms sold, ADR, and income are transformed to their the natural logarithm $(\mathrm{In})$ form. This revision appears as Equation (2).

InRooms Sold = $\mathrm{f}\left(\right.$ InADR, InIncome, Change in Employment, Seasonal Adjustments, InRooms Sold $\left.{ }_{-1}\right)$

The directions (i.e., signs) of the expected relationships presented in Exhibit 1 do not changes with the log transformation. Using data from Smith Travel Research and Moodys Analytics, we estimate both the short- and long-run price and income elasticity for all hotels, chain scale segments, and selected city hotel markets. Short- and long-run elasticity numbers are produced following the process described in Appendix A.

Conventional economic wisdom holds that demand is more elastic in the long run than the short run. In the short run, buyers have little time to find alternative accommodations or change their destination and therefore are not highly price-sensitive. Also in the short-run, the number of available rooms is largely fixed. Conversely in the long-run, assuming a price change is permanent, buyers have time to react to new pricing. With time to react to changes in market conditions, rooms can be added to the supply by building new hotels and converting other property types into additional hotel rooms. 
We estimate elasticity at the aggregate level for all U.S. hotels and at disaggregate levels for national chain scales and selected city hotel markets to provide a broadened perspective on hotel price and demand relationships. The problem of aggregation bias has been examined in macroeconomics, urban economics, and hotel revenue management. ${ }^{2}$ Adding observations through aggregation increases statistical power and efficiency, but also may reduce forecasting accuracy and understanding of underlying behavioral relationships that comes from analyzing micro-level data. Aggregation bias can be summarized as the problem of macro parameters, in this instance price elasticity of all U.S. hotel demand, deviating from the averages of the component micro parameters - the elasticity of chain scales and local markets.

\section{Price Elasticity Estimates}

The results for U.S. hotels aggregated by chain scale (i.e., all hotels), top 50 markets, and selected cities appear in Exhibit 4. At the most aggregate levels (i.e., all hotels and top 50 markets), inelastic price and demand relationships are found in the short run and long run. These results may be due to the fact that at the national level there are limited alternatives for accommodation. If all the hotels in the U.S. increase their rates by the same amount, for example, there will be only a small decline in demand. As the group of hotels analyzed becomes more narrowly defined, we find higher price elasticity. Prices increases in a particular chain scale or city may incentivize people to choose an alternative city or type of accommodation thereby decreasing demand in the market experiencing the relative price increase.

We see the effects of disaggregation in the long-run price elasticity of upper priced hotels in the top 50 markets $(-0.84)$ compared to the same estimates for all hotels in the top 50 markets $(-0.37)$ and all hotels in the U.S. (-0.19). These estimates suggest some aggregation bias exists and therefore we expect by extension that the elasticity for individual hotels will be higher than their market level elasticity suggests. At a property level, a hotel that significantly lowers its price could potentially take demand away from competing hotels and capture more demand then could be captured by lowering price at a city wide or chain scale level. Hence, the estimates presented here cannot be directly applied to an individual hotel or even a competitive set of hotels. They are useful for interpreting differences in demand responsiveness to price changes among types of hotels. For example, we estimate the price elasticity of luxury hotels to be four times the price elasticity of economy hotels.

\footnotetext{
${ }^{2}$ See, for examples, one of the original articles on aggregation by Theil (1954), an excellent analysis of aggregation problems when examining local housing markets by Goodman (1998), and the effects of aggregation on hotel revenue forecasting accuracy by Weatherford, Kimes, and Scott (2001).
} 


\section{Exhibit 4: Price Elasticity Results}

\begin{tabular}{lcc}
\multicolumn{1}{c}{ Performance Measure } & $\begin{array}{c}\text { Short-Run Price } \\
\text { Elasticity }\end{array}$ & Long-Run Price Elasticity \\
\hline Chain Scales & -0.17 & \\
All & -0.70 & -0.19 \\
Luxury & -0.32 & -1.36 \\
Upper Upscale & -0.31 & -0.34 \\
Upscale & -0.42 & -0.75 \\
Upper Midscale & -0.14 & -1.11 \\
Midscale & -0.08 & -0.20 \\
Economy & -0.12 & -0.29 \\
Independent & & -0.16 \\
& & \\
Top 5o Markets & -0.15 & \\
All & -0.22 & -0.37 \\
Upper Priced & -0.09 & -0.84 \\
Lower Priced & & -0.64 \\
& & \\
Select Cities & -0.59 & \\
Baltimore - Upper Priced & -0.26 & -0.59 \\
Baltimore - Lower Priced & -0.45 & -0.43 \\
Detroit - Upper Priced & -0.06 & -1.74 \\
Detroit - Lower Priced & -0.31 & -0.15 \\
New York - Upper Priced & -0.13 & -0.54 \\
New York - Lower Priced & -0.51 & -0.19 \\
San Francisco - Upper Priced & -0.14 & -0.67 \\
San Francisco - Lower Priced & -0.22 & -0.17 \\
San Diego - Upper Priced & -0.13 & -0.69 \\
San Diego - Lower Priced & & -0.27 \\
\hline
\end{tabular}

Source: PKF Hospitality Research, LLC

\section{Income and Quantity Demanded - Income Elasticity}

The effects of changes in rooms sold resulting from changes in other demand determinants in Equation (1) are represented as shifts in the demand curve instead of changes in the slope. Econometric testing at PKF-HR indicates that, along with ADR, real personal income typically has the most consistent and strongest effect on the number of rooms sold in U.S. hotels. Because income and hotel demand are positively related, increases in household and business incomes translates into additional hotel rooms sold. In Exhibit 5, the hotel demand curve is presented under circumstances when incomes rise and fall. Curve $\mathrm{D}_{4}$ illustrates the scenario in which only an increase in income levels occurs, resulting in a shifting 
of the curve to the right. Curve $D_{5}$ illustrates the scenario where only a decrease in income levels occurs, resulting in a shifting of the curve to the left. The elasticity of rooms sold with respect to income indicates how much demand is induced and reduced by changes in income.

\section{Exhibit 5: Shifts in the Hotel Demand Curve from Income Changes}

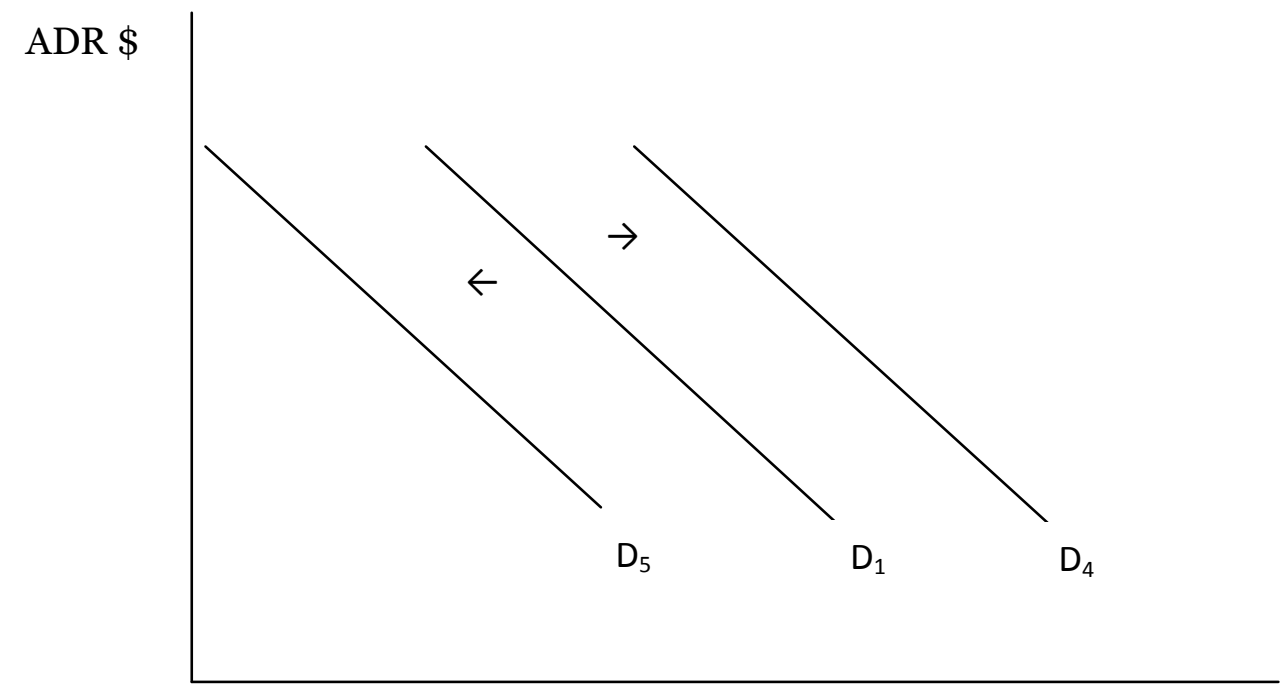

Number of Rooms Sold

When analyzing the income elasticity of demand, we expect similar aggregation bias as with price elasticity estimation. This bias comes from the different types of goods sold across the spectrum of hotels. Goods and services can be defined according to their income elasticity. These are,

- Superior good - income elasticity > 1. For example, if income rises by one percent the household or business increases consumption of that good by more than one percent.

- $\quad$ Normal good - income elasticity $=1$.

- Inferior good - income elasticity $<1$.

Typically, luxury products have income elasticity $>1$ and are classified as superior goods while necessities generally have income elasticity $<1$ and thus are classified as inferior goods. We expect that higher price/quality hotels will have noticeably greater income elasticity than lower price/quality hotels. 
As expected, we find quite different income elasticity across hotel chain scales and price categories with larger elasticity for the upper-price/quality hotels and a smaller elasticity for the lowerprice/quality hotels as shown in Exhibit 6. These differences generally hold true at the national level, among chain scales, but not always at the city level. Upper-price hotels, largely due to their reliance on corporate and group demand, and thereby corporate profits, experience relatively large demand increases for a corresponding increase in income. For example, a one percent increase in income in New York corresponds with a 1.19 percent increase in demand for upper-priced hotels, but only a 0.46 percent increase in demand for lower-priced hotels. That contrasts with the small differences in income elasticity estimates for San Francisco, 0.29 for upper priced hotels compared 0.67 for lower priced hotels. This suggests that income is generally inelastic for the San Francisco market.

\section{Exhibit 6: Income Elasticity Results}

\begin{tabular}{lcc}
\multicolumn{1}{c}{ Performance Measure } & $\begin{array}{c}\text { Short-Run Income } \\
\text { Elasticity }\end{array}$ & $\begin{array}{c}\text { Long-Run Income } \\
\text { Elasticity }\end{array}$ \\
\hline Chain Scales & & \\
All & 0.56 & 0.62 \\
Luxury & 1.09 & 2.12 \\
Upper Upscale & 0.63 & 0.67 \\
Upscale & 0.82 & 2.02 \\
Upper Midscale & 0.47 & 1.23 \\
Midscale & 0.27 & 0.38 \\
Economy & 0.12 & 0.66 \\
Independent & 0.05 & 0.07
\end{tabular}

\section{Top 50 Markets}




$\begin{array}{lll}\text { All } & 0.30 & 0.73 \\ \text { Upper Priced } & 0.27 & 1.01 \\ \text { Lower Priced } & 0.06 & 0.43\end{array}$

\section{Select Cities}

\begin{tabular}{lll} 
Baltimore - Upper Priced & 0.72 & 0.73 \\
Baltimore - Lower Priced & 0.35 & 0.57 \\
Detroit - Upper Priced & 0.42 & 1.66 \\
Detroit - Lower Priced & 0.27 & 0.65 \\
New York - Upper Priced & 0.67 & 1.19 \\
New York - Lower Priced & 0.30 & 0.46 \\
San Francisco - Upper Priced & 0.22 & 0.29 \\
San Francisco - Lower Priced & 0.79 & 0.67 \\
San Diego - Upper Priced & 0.22 & 0.68 \\
San Diego - Lower Priced & 0.22 & 0.46 \\
\hline
\end{tabular}

Source: PKF Hospitality Research, LLC

\section{Application}

Using our Hotel Horizons ${ }^{\circledR}$ demand model we insert different levels of ADR for 2012 and record the corresponding room demand forecast for 2012. As seen in Exhibit 7, the U.S. demand curve $\left(\mathrm{N}_{1}\right)$ has the usual decreasing slope. As ADR levels increase, a corresponding decrease occurs in the number of rooms sold in the U.S. for 2012. The U.S. demand curve presented in Exhibit 7 has an elasticity of -0.19 , which as mentioned earlier, is very inelastic due to the level of data aggregation. The demand curve shows that at a forecasted ADR level of $\$ 108\left(P_{1}\right)$, we would expect to see $2,928,000\left(Q_{1}\right)$ rooms sold per day during 2012. As the ADR level moves, only a small change in the corresponding demand is recorded. At an ADR level of $\$ 104$, a 3.8 percent decrease, we see a demand increase of only 16,000 rooms to $2,944,000\left(Q_{4}\right)$ which is approximately a 0.6 percent change.

We apply the same concept to looking at changes in income. Since we are keeping everything else constant and only changing the level of income, we see a shift in the demand curve. To do this, we test two of Moody's Analytics' alternative scenario forecasts from the baseline scenario (N1) in our demand equation. The first scenario assumes a slightly better forecast for 2012. The corresponding demand outputs are plotted in line $\mathrm{N}_{2}$. The 0.9 percent increase in income leads to a corresponding 0.5 percent increase in demand, from $Q_{1}$ to $Q_{2}$, or 14,000 room nights. 
This same sequence is repeated with a weaker forecast for 2012, which assumes soft income growth throughout the year. This decrease in the forecast of income causes the line $\left(\mathrm{N}_{3}\right)$ to shift to the left and therefore a decrease to our demand forecast. In this example, Moody's has decreased its income forecast by 1 percent. This shift leads to a new demand level of Q3, which is around 0.6 percent less than $\mathrm{Q}_{1}$, or 17,000 room nights. These alternative scenarios give insight into what could happen in the lodging market if Moody's forecasts of future economic growth are not exact.

Exhibit 7: 2012 U.S. National Demand Curve:

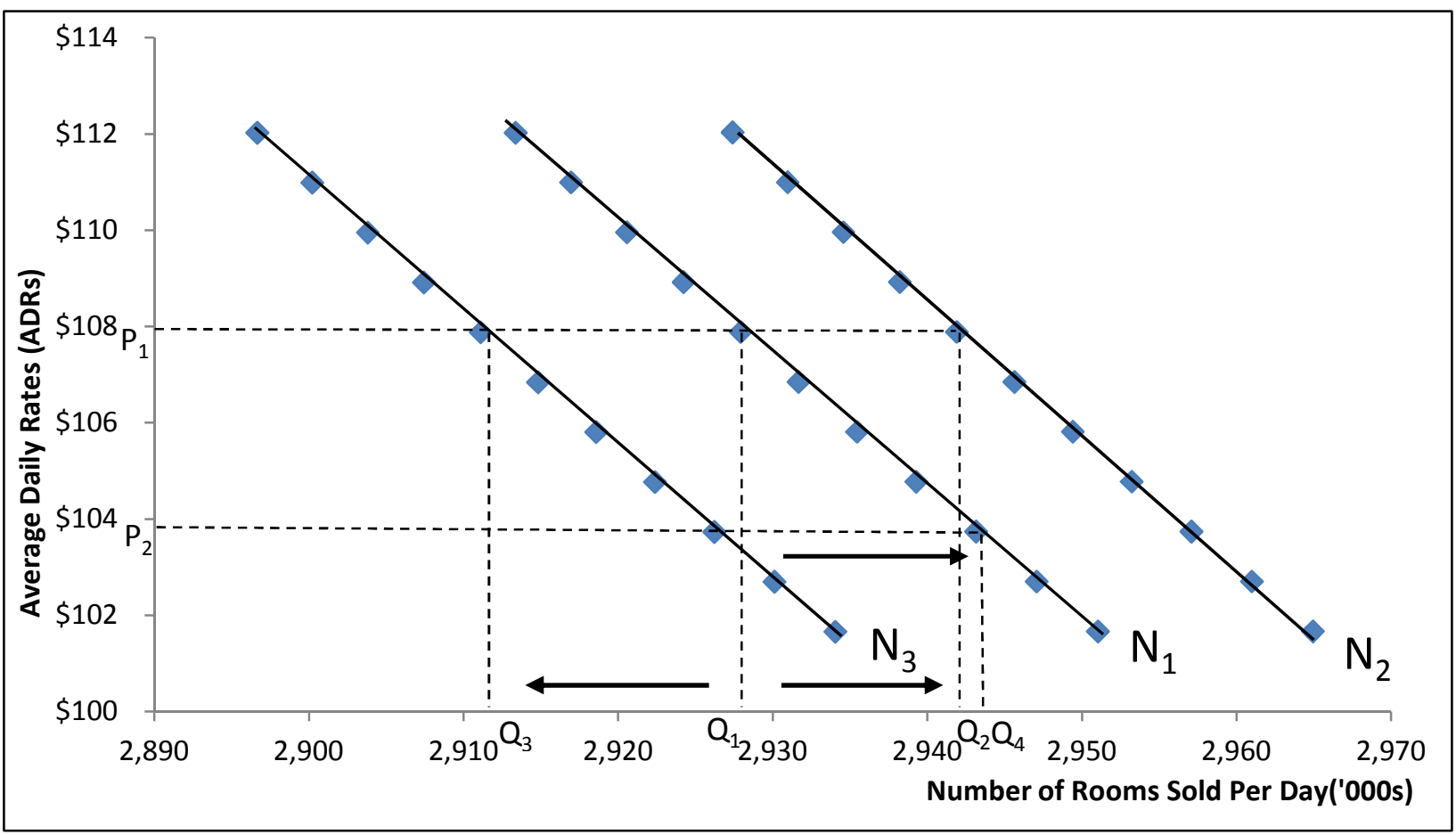

By knowing the elasticity of your market, you can find out what the change in demand will be given any future change in income or price by multiplying the elasticity by that change in income or price. Therefore, instead of testing these outputs from within our model, we could have multiplied our one percent increase in income by the U.S. all hotel's income elasticity (0.62) and obtain the same 0.6 percent increase in demand. If we apply that methodology to the other chain scales and markets, much larger shifts in demand will occur for the same change in income of upper priced scales than in lower priced due to different sizes of the elasticity coefficient computed for each scale.

\section{Conclusion}

The demand curves for a hotel, local hotel market, chain scale, and entire nation graphically represent perhaps the most important phenomenon for understanding historical and future hotel 10 | P a g e 
financial performance - how demand relates to ADR. The slope of the demand curve on a twodimensional graph provides visual evidence of the price elasticity of hotel demand defined as the percent change in demand given a percent change in ADR. From our analysis, price elasticity varies depending on the level of data aggregation (e.g., national level to property level), on whether the estimate is short term or long term, and potentially on how the elasticity is econometrically estimated. In addition to price, hotel demand curves also shift because of changes in the economic environment. The most important of these 'shifters' is a change in income. The magnitudes of the shifts are indicated by the income elasticity - the percentage change in demand given a percentage change in income.

Our contributions in this article are as follows: First, we estimate an updated set of price and income elasticity numbers from data through 2011 for the nation, chain scales, and selected city markets. Second, we perform these estimates using a multivariate demand equation taken from PKF-HR's Hotel Horizon ${ }^{\circledast}$ forecasting platform. The multivariate estimation procedure ensures that elasticity is estimated while controlling for other important demand determinants. Third, elasticity is generated for markets reaching long-run equilibrium as well as in the short run. In the long run, consumers have the opportunity to adjust their behaviors and the supply of hotel rooms will adjust to new price and demand levels.

Our findings are consistent with estimates produced by others for short-run elasticity, but we report sometimes noticeable differences between long-run and short-run elasticity. Hotel demand is more price elastic in the long run. Price and income elasticity also are considerably larger for higher quality hotels as indicated by the chain scale in which they operate. Elasticity tends to increase with data disaggregation. Higher elasticity is generally found for individual chain scales and cities compared to the nation.

Knowledge of price and income elasticity improves hotel managements' ability to anticipate the number of rooms that will be sold as room rates and economic conditions change. In applying these results to an individual hotel or group of hotels we recommend that: elasticity should be estimated using a fully specified demand model, elasticity should be estimated in long-run equilibrium and compared to shortrun estimates, and elasticity should be estimated with consideration for how the number will be used. For example, using a national price elasticity to understand the demand responsiveness to changes in room rate for an individual hotel will likely yield misleading conclusions.

\section{References}

11 P a g e 
Goodman, J.L. Jr. 1998. Aggregation in Local Housing Markets. Journal of Real Estate Finance and Economics, 16(1): 43-53.

Green C.E. and M. Lomanno. 2012. Distribution Channel Analysis: A Guide for Hotels. Hospitality Sales \& Marketing Association International Foundation.

PriceWaterhouseCoopers. 2005. Price Elasticity of Lodging Demand. Hospitality Directions (September).

Thiel, H. 1954. Linear Aggregation of Economic Relations. Amsterdam: North-Holland Press.

Weatherford L.R, S.E., Kimes, and D.A. Scott. 2001. Forecasting for Hotel Revenue Management: Testing Aggregation Against Disaggregation. Cornell Hotel and Restaurant Administration Quarterly 42 (August): 53-64.

\section{Appendix A: Calculation of Short and Long-Run Elasticity}

We model hotel demand within a single equation, partial adjustment framework using ordinary least squares. The partial adjustment model assumes a market moves toward equilibrium at an estimated speed of adjustment. The speed of adjustment parameter is determined from the parameter of the lagged dependent variable as shown below. This parameter allows for the calculation of long-run elasticity.

We begin with the estimating equation with variables measured in levels transformed to natural logs.

InRooms Sold $=\beta_{1}+\beta_{2} \ln A D R+\beta_{3} \ln \operatorname{lncome}+\beta_{4}$ Change in Employment + Seasonal Adjustments $+\beta_{5} \operatorname{lnRooms}$ Sold -1 where the variables are defined in the text.

The short-run price and income elasticity are taken directly from the estimated model parameters as follows:

- $\quad$ Short-Run Price Elasticity $=\beta_{2}$

- $\quad$ Short-Run Income Elasticity $=\beta_{3}$

To compute the long-run elasticity of price and income we make use of the speed of adjustment parameter ( 1 - $\beta_{5}$ ) as a scaling factor applied to the estimated short-run price and income elasticity, as follows,

- Long-Run Price Elasticity $=\beta_{2} /\left(1-\beta_{5}\right)$

- $\quad$ Long-Run Income Elasticity $=\beta_{3} /\left(1-\beta_{5}\right)$ 
Jack Corgel, Robert C. Baker Professor of Real Estate, School of Hotel Administration, Cornell University and Senior Advisor to PKF Hospitality Research, LLC. Jamie Lane is an Economist with PKF Hospitality Research, LLC. Mark Woodworth is President of PKF Hospitality Research (PKF-HR), LLC, an affiliate of PKF Consulting USA (PKF/C), (PKF/C), Atlanta, GA.

13 I $\mathrm{P}$ a g e 